\title{
Bioluminescence to reveal structure and interaction of coastal planktonic communities
}

\author{
Mark A. Moline ${ }^{\mathrm{a}}$, Shelley M. Blackwell ${ }^{\mathrm{a}}$, James F. Case ${ }^{\mathrm{b}}$, Steven H.D. Haddock ${ }^{\mathrm{c}}$, Christen M. Herren ${ }^{\mathrm{c}}$, \\ Cristina M. Orrico ${ }^{b}$, Eric Terrill ${ }^{\mathrm{d}}$ \\ a Biological Sciences Department, California Polytechnic State University, 1 Grand Avenue, San Luis Obispo, CA 93407, USA \\ ${ }^{\mathrm{b}}$ Marine Science Institute, University of California Santa Barbara, Santa Barbara, CA 93106, USA \\ ${ }^{\mathrm{c}}$ Monterey Bay Aquarium Research Institute, Moss Landing, CA 95039, USA \\ d Marine Physics Laboratory, Scripps Institution of Oceanography, La Jolla, CA 92093, USA
}

\begin{abstract}
A B S T R A C T
Ecosystem function will in large part be determined by functional groups present in biological communities. The simplest distinction with respect to functional groups of an ecosystem is the differentiation between primary and secondary producers. A challenge thus far has been to examine these groups simultaneously with sufficient temporal and spatial resolution for observations to be relevant to the scales of change in coastal oceans. This study takes advantage of general differences in the bioluminescence flash kinetics between planktonic dinoflagellates and zooplankton to measure relative abundances of the two groups within the same-time space volume. This novel approach for distinguishing these general classifications using a single sensor is validated using fluorescence data and exclusion experiments. The approach is then applied to data collected from an autonomous underwater vehicle surveying $>500 \mathrm{~km}$ in Monterey Bay and San Luis Obispo Bay, CA during the summers of 2002-2004. The approach also reveals that identifying trophic interaction between the two planktonic communities may also be possible.
\end{abstract}

\section{Introduction}

Coastal regions are responsible for approximately $30 \%$ of global ocean productivity (Holligan and Reiners, 1992) and, as such, are zones of the highest biogeochemical cycling per area with respect to carbon, nitrogen, phosphorus, and trace metals (Ducklow and McCallister, 2005; Jahnke, 2005). Mediation, persistence, and variability of these rates of biogeochemical cycling are primarily driven by the structure and activity of biological communities. These communities are, in turn, organized non-randomly, and can be layered relative to the physical structure of water and distribution of nutrients, by advective processes and by behavioral differences within and between organisms (Deutschman et al., 1993). Because of these varied mechanisms for accumulation (or patch formation) of different planktonic organisms, their horizontal and vertical distributions are often heterogeneous, vary between organisms, and are scaled to the physical, chemical, and biological forcing. The size of these patches also generally scales inversely to the organisms' size (Levin, 1992), with the largest patches represented by autotrophic phytoplankton, and less concentrated larger heterotrophic organisms in successively smaller patches (Hall and Raffaelli, 1993). Maximal trophic interactions, transfer of carbon, and rates of biogeochemical cycling thus occur when these highly concentrated predator and prey fields intersect. Because of the high rates and levels of activity in coastal systems, the mechanisms governing patch distribution and coherence of organisms and their biological interactions are major topics of ongoing research.

While clearly important, assessing the distribution of plankton and particularly their interactions have been challenges for oceanographers. This, in part, stems from the array of approaches used to quantify planktonic communities in situ, and the distinction between approaches specific for zooplankton versus phytoplankton. Bio-optical approaches, such as fluorometry, have successfully delineated autotrophic populations and communities in situ for many years (Yentsch and Menzel, 1963; Lorenzen, 1966). More recently, in situ absorption has been used as a tool to assess phytoplankton concentrations (Moore, 1994), as well as separate out specific functional groups (Schofield et al., 2004) or species, such as harmful algae (Kirkpatrick et al., 2000), based on their pigment signatures. Similarly, ocean acoustic approaches have been developed to map zooplankton and nekton (Johnson, 1948; Holliday and Pieper, 1980; Flagg and Smith, 1989). Recent advancements in multi-frequency acoustics have been able to 
distinguish between zooplankton groups and species (Holliday et al., 1989; Pieper et al., 1990; Cochrane et al., 2000; Benoit-Bird and $\mathrm{Au}, 2003$ ). While both bio-optical and acoustic approaches provide significant information on the distribution and concentration of phytoplankton and zooplankton at a range of sizes and groups, in situ measurements are rarely concurrent and at different scales, making synthesis and integration difficult. Additionally, uncertainty in the spatial and temporal intersection of these communities limits the extent of our understanding of the trophic interaction and thus the nature, rates, and scales of coastal biogeochemical cycling. These uncertainties have also played a role in limiting the extent to which biology has been integrated into dynamical regional ocean models, which have significantly advanced with respect to physical oceanography (Kantha and Clayson, 2000). A measurement is therefore needed that can provide simultaneous data for different planktonic communities at time and space resolutions similar to routine oceanographic parameters, such as temperature, salinity, and fluorometry.

The measure of bioluminescence or bioluminescence potential (BP) has been reported in the literature for some time (Clarke and Wertheim, 1956; Clarke and Kelley, 1965; Seliger et al., 1969). Early research on this phenomenon was driven primarily by the desire to understand physiological mechanisms for bioluminescence, as well as the ecological advantage that bioluminescence affords to organisms (Alberte, 1993). Previous work in marine bioluminescence can be divided into a number of categories and depends largely on the level of organization. Bioluminescence is produced by over 700 genera representing 16 phyla, spanning the range of small single-cell bacteria to large vertebrates (Herring, 1987). As such there have been a number of studies examining the phenomena on individual, population, and ecosystem levels. On the organism level, the physiological and cellular basis for bioluminescence (Rees et al., 1998), the spectral quality and flash kinetics of bioluminescence (Latz et al., 1988; Haddock and Case, 1999), and how these relate to aspects such as circadian rhythms (Soli, 1966; Morse et al., 1989), photosynthesis (Johnson et al., 1998), and diet (Haddock et al., 2001) have been well documented. On a population level, bioluminescence has been studied as it relates to predator avoidance, prey attraction, and intra-species communication (Burkenroad, 1943; Morin, 1983; Morin and Cohen, 1991; Abrahams and Townsend, 1993).
Another body of literature has attempted to examine spatial and temporal variability in bioluminescence from a community and ecosystem perspective. In approaching this problem, in situ sensors, called bathyphotometers, are employed to quantify the amount of BP and community structure of bioluminescent organisms in a particular body of water and relate these patterns to the local- or ecosystem-level dynamics. Case et al. (1993) and Alberte (1993) review the development of bathyphotometers and patterns of oceanic bioluminescence. Although developed in 1950 s, one of the first large-scale applications of bathyphotometers took place in late 1980s in North Atlantic to examine the differences in light production by various planktonic taxa (Batchelder and Swift, 1989; Losee et al., 1989; Batchelder et al., 1990, 1992; Swift et al., 1995). These measurements are becoming more prevalent and have now been conducted off ships, on profiling and undulating systems, on moorings, and on autonomous underwater vehicles (AUVs; Widder et al., 1993; Moline et al., 2001, 2005; Herren et al., 2005). These efforts have provided new insight into the distribution of coastal bioluminescence at ecosystem scales as it relates to physical forcing and physiological rhythms (Widder et al., 1999; Shulman et al., 2003, 2005; Moline et al., 2005).

From this body of work, there have been a number of general relationships that have been derived from the measurement of marine bioluminescence. For a given planktonic community (highly dependent on locale and season), the number of bioluminescent organisms and total bioluminescence are proportional to the total biomass (Lapota, 1998). The intensity of bioluminescent flash and duration of flash have also been shown to correlate with the size of organism (Lapota and Losee, 1984; Lapota et al., 1992). Because of this general difference, bioluminescence flash kinetics can be used to delineate these groups (Fig. 1). Even though larger bioluminescent organisms generally produce more light, in locally stable environments, their numbers are proportionally lower relative to smaller single-celled dinoflagellates. The majority of coastal BP scales inversely with the size spectrum, with dinoflagellates generally responsible for the majority of the signal (70-90\%; Lapota et al., 1988; Swift et al., 1995).

Here we use the general relationship between bioluminescence flash intensity with organism size to interpret signals measured from a bathyphotometer deployed on an AUV during

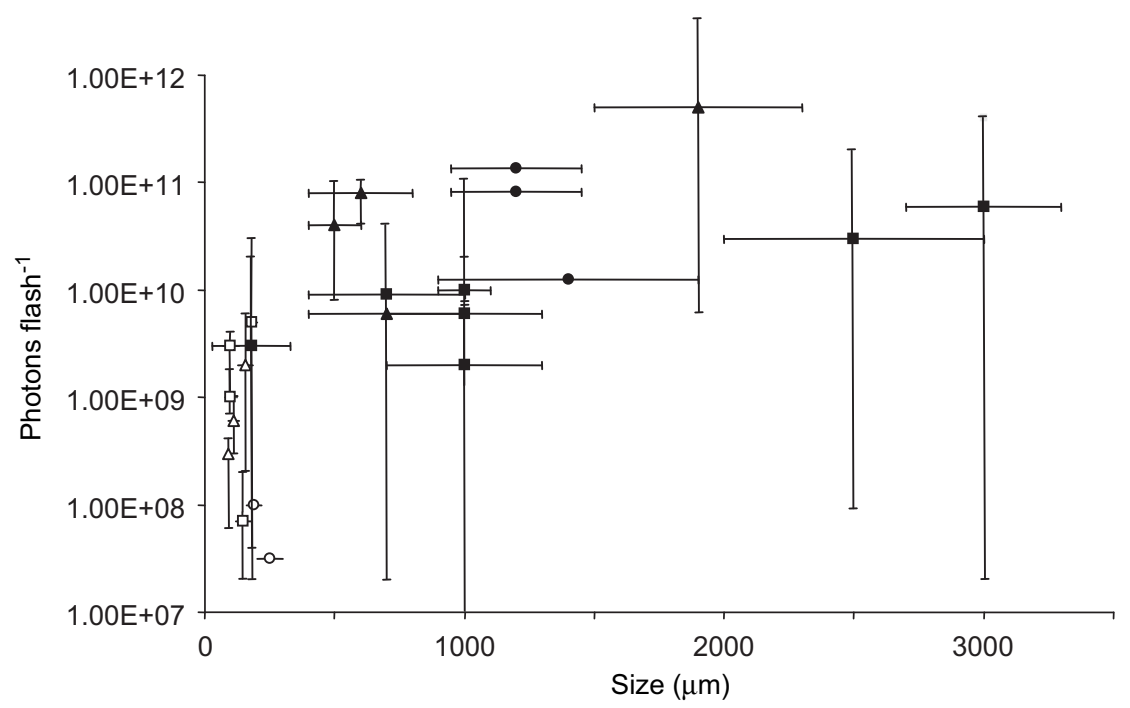

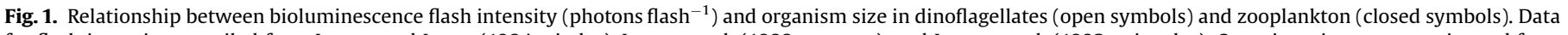

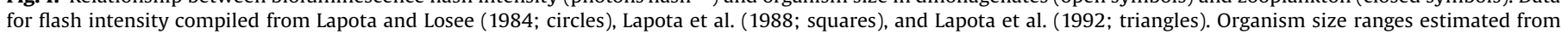
Thomas (1997) and Johnson and Allen (2005). 
2002 and the 2003 Autonomous Sampling Observation Network II (AOSN-II) experiment in Monterey Bay and develop a means to distinguish and delineate the general structure of coastal planktonic communities and their interactions. This approach may complement traditional measurements and serve to validate or access uncertainties over relevant scales.

\section{Methods}

\subsection{Bioluminescence measurement}

The bioluminescence bathyphotometer used in this study to quantify BP is described in Herren et al. (2005). A centrifugal-type impeller pump drives water into an enclosed 500-ml chamber and creates turbulent flow, which mechanically stimulates bioluminescence. The measure of BP is therefore an index of the total luminescent capacity of organisms in a set water volume. The measure assumes similar flow-stimulation characteristics for different groups of organisms and is dependent on the characteristics of the bathyphotometer, which can vary significantly ( $c f$.
Herren et al., 2005). Here, a light-baffled photomultiplier tube (PMT) measures stimulated light between 300 and $650 \mathrm{~nm}$ produced by the entrained organisms. The inside of the chamber is coated with a $0.075-\mathrm{mm}$ flat white coating to maximize the amount of stimulated light measured by the PMT. The PMT was configured to take measurements at $2 \mathrm{~Hz}$. The flow rate through the chamber is dependent on the rotation rate of the impeller rotor. This rate is adjusted to achieve residence times of $1.2-1.4 \mathrm{~s}$, or flow rates of approximately $400 \mathrm{ml} \mathrm{s}^{-1}$. A flow meter monitors pumping rates using a magnet and a Hall-effect sensor to generate a period signal, which is converted to an analog signal of flow rate. The flow rates are measured as water passes from the detection chamber to exhaust outlets. The bioluminescence bathyphotometer was integrated into the front section of a Remote Environmental Monitoring UnitS (REMUS) AUV system (Fig. 2A; Moline et al., 2001, 2005; Blackwell, 2002; Herren et al., 2005). In order to prevent premature stimulation of bioluminescence by the moving vehicle, water is taken directly through the front nose section of the vehicle. Two light-baffling turns in the nose serve to minimize ambient light contamination. No significant ram effect on light production or flow rate from the vehicle itself was found

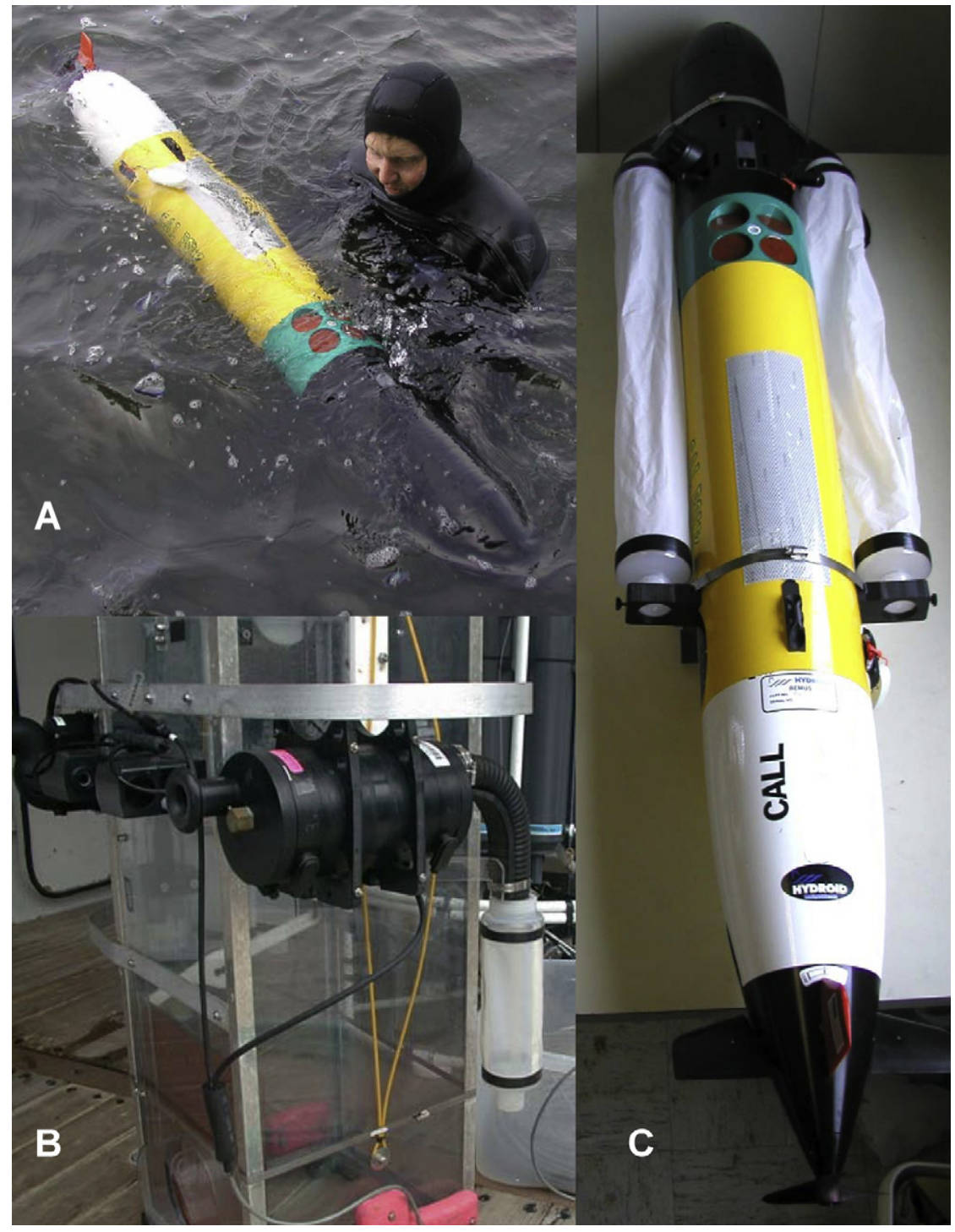

Fig. 2. (A) The REMUS autonomous underwater vehicle used in this study being deployed in San Luis Obispo Bay, CA. Integrated into the nose section of the vehicle is the bathyphotometer for quantification of bioluminescence (see text). (B) Two bathyphotometers attached to a Schindler trap for method validation in this study. Screened bottles were placed on the exhausts of the bathyphotometers to collect organisms for quantification and identification. (C) The REMUS with similar bottles attached to the bathyphotometer exhaust ports to capture organisms for validation tests. 
with this integrated system. Two additional bioluminescence bathyphotometers were used in profiling mode as part of validation tests (see below). Cross-calibration between the three instruments was ensured using a standard isotropic light source probe inserted into the individual stimulation chambers (Herren et al., 2005).

\subsection{Sampling approach}

Data for this study were collected from Monterey Bay in August 2002 and 2003 as part of the AOSN-II experiment, and in San Luis Bay in June/September 2004 (Fig. 3). Sampling with the REMUS in Monterey Bay in 2002 occurred along transect "a" while in 2003, sampling was conducted along transects "a" and "b", each approximately $21 \mathrm{~km}$ in distance. REMUS sampling was conducted in San Luis Obispo Bay along a cross-shore transect, while profile sampling occurred off the California Polytechnic State University's Center of Coastal Marine Sciences pier. All sampling for this study was conducted between 22:00 and 04:00 local time as BP is a diurnally dependent measure, but it has been shown to be generally stable during this 6-h period (Moline et al., 2001).

In Monterey Bay, the REMUS was programmed to undulate between 4- and 40-m depth at a speed of approximately $2 \mathrm{~m} \mathrm{~s}^{-1}$ Navigation of the AUV was by an internal compass corrected for by onboard-measured 3-D currents (Moline et al., 2005). Navigational error over the combined REMUS runs for this study was $\sim 1.7^{\circ}$ of distance covered. For sampling in San Luis Obispo Bay, the REMUS was programmed to travel across a $400-\mathrm{m}$ transect at constant depths of 2 and $6 \mathrm{~m}$ along the $12-\mathrm{m}$ isobath. Twenty- $\mu \mathrm{m}$ nets were attached to the exhaust ports of the REMUS during these deployments to capture the organisms going through the sampling chamber (Fig. 2C). The REMUS was deployed with this

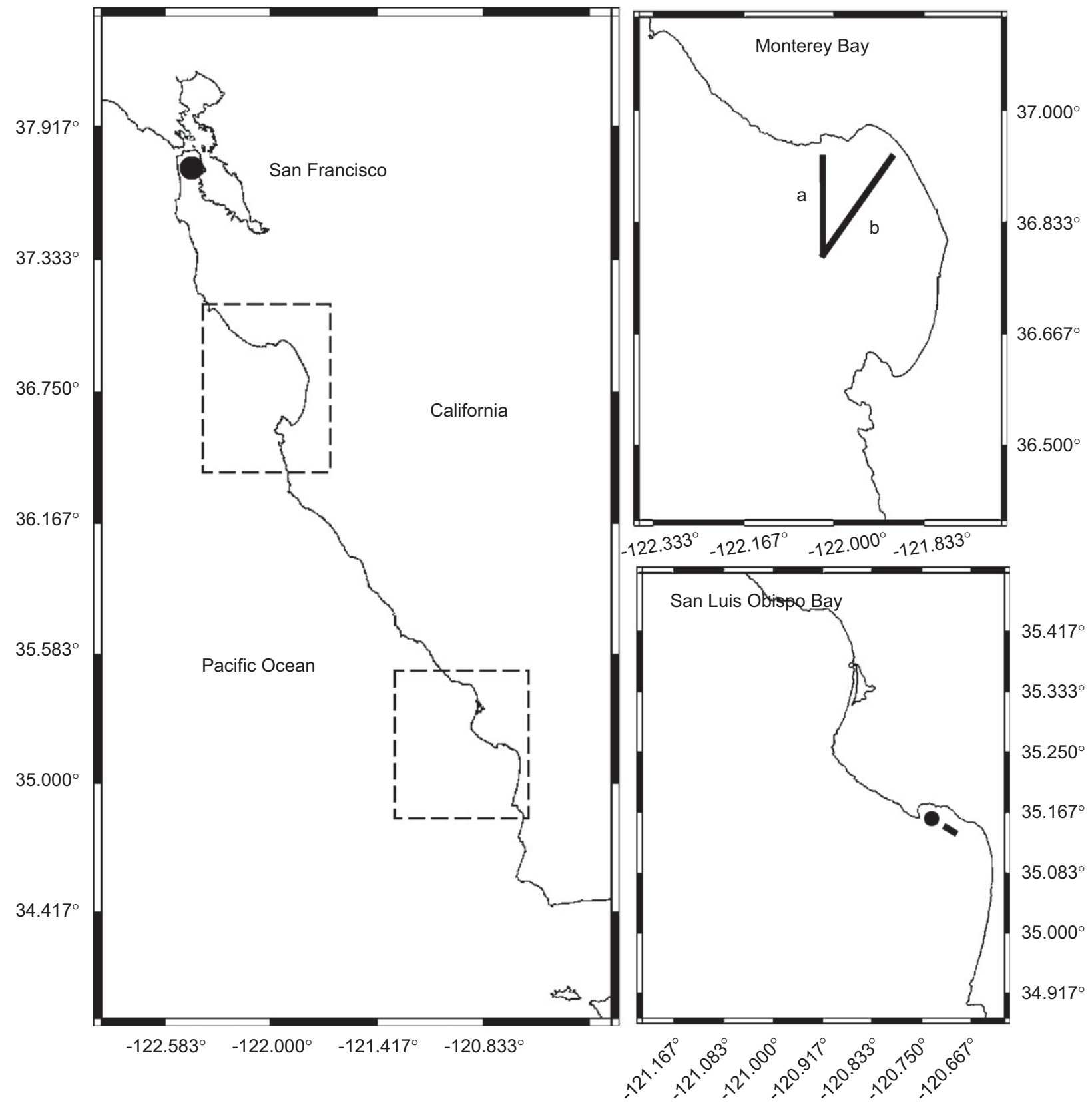

Fig. 3. Study areas (insets) in relation to the central coast of California. Monterey Bay was the site of the REMUS deployments along two transect lines ("a" and "b") during August 2002 and 2003. San Luis Obispo Bay was the location for validation tests with the autonomous profiler (circle) and the REMUS in 2004 (black line). 
net configuration twice in San Luis Obispo Bay along the two depths. During the second deployment, for the purpose of excluding larger plankton from the excitation chamber, an additional $190-\mu \mathrm{m}$ net was placed between the light-baffling nose and the bathyphotometer, $0.25 \mathrm{~cm}$ from the impellor to prevent pre-stimulation of bioluminescence. Given the flow rate of the bathyphotometer $\left(\sim 400 \mathrm{ml} \mathrm{s}^{-1}\right)$ and the diameter of the intake $(3.2 \mathrm{~cm})$, the time between the screen and the impellor (where the stimulation is designed to occur) was $5 \mathrm{~ms}$, which is significantly lesser than the flash response latency of these organisms (Widder and Case, 1981).

In San Luis Obispo Bay, a bioluminescence bathyphotometer was attached to a Schindler sampling trap (Fig. 2B). The sampler was suspended at the depth of peak bioluminescence $(2.5 \mathrm{~m})$ for $3 \mathrm{~min}$. The intake of the bathyphotometer was alternately prescreened with a $190-\mu \mathrm{m}$ screen or not screened (see above). Initially, a large-mesh $\sim 2500-\mu \mathrm{m}$ pre-screen was also used to examine effects of pre-stimulation and impact of screening on the organism. There were no significant differences in number or type of organisms or bioluminescence signal between the large-mesh control and the non-screened treatment (data not shown). We therefore report only the $190-\mu \mathrm{m}$ pre-screen and non-screen conditions. In both of these conditions, the exhaust water from the bathyphotometer was screened through a $20-\mu \mathrm{m}$ screen to capture organisms that traveled through the instrument for identification and enumeration. There was no visible impact of the bathyphotometer on the structure of either phytoplankton or zooplankton. Plankton were identified in a 100-ml settling chamber using an inverted microscope.

\subsection{Signal processing}

The variance and mean BP for a given location were calculated from a sliding data window. The size of the sliding window was equivalent to $25 \mathrm{~m}$ linear distance traveled by the REMUS vehicle for data collected in Monterey Bay and San Luis Obispo Bay and was objectively determined by identifying the length scales of variability, detailed in Moline et al. (2005) and Blackwell et al. (2007). For the time series tests performed with the profiling bathyphotometers a data window of $12.5 \mathrm{~s}$ was used (25 observations). The square root of variance of BP and mean BP were used to generate the coefficient of variation (CV) used in this study. This approach highlights the differences in bioluminescent flash intensity rather that flash duration as a means to separate dinoflagellates and zooplankton. While flash duration is certainly important and contains species-level information (Widder et al., 1993), it is problematic for many studies using bathyphotometers as residence times of these instruments vary ( $c f$. Herren et al., 2005) and are shorter than flash durations of many organisms. The simple volume replacement time calculated for the bathyphotometer is on the order of a second; however, it is clear that a decreasing number of organisms can be retained within the flow field for longer periods (6-10 s; Herren et al., 2005). Because of this uncertainty in retention and the strong correlation $\left(R^{2}=0.81\right.$; exponential fit) between flash intensity and duration (Lapota and Losee, 1984), we have focused on intensity in this study.

\section{Results and discussion}

\subsection{Coastal dynamics}

Data from the REMUS deployments in Monterey Bay in 2002 showed significant coefficient of variability in both physical and biological fields (Fig. 4). The cross-shore transect was characterized by a stratified water column with evidence of upwelled water out to $5 \mathrm{~km}$. This pattern is consistent with a recurring cyclonic eddy that forms in Monterey Bay during upwelling periods (Shulman et al., 2003). Phytoplankton were layered inshore of $5 \mathrm{~km}$ with a deeper and more diffuse distribution between 5 and $10 \mathrm{~km}$ offshore. At $10 \mathrm{~km}$, there was a twofold decrease in phytoplankton biomass in surface waters associated with a salinity front. The depth distribution of high BP was also shallower inshore of $5 \mathrm{~km}$ and deeper between 5 and $10 \mathrm{~km}$ offshore, similar to fluorescence, although the higher BP values were more concentrated at depth. There were areas of high BP measured offshore of $15 \mathrm{~km}$, near the bottom inshore, and on the offshore side of the front at $5 \mathrm{~km}$ that did not co-occur with high values of fluorescence.

In regions where both $\mathrm{BP}$ and fluorescence are high, the traditional interpretation is that the majority of bioluminescent community is autotrophic (Lieberman et al., 1987; Lapota, 1998; Geistdoerfer and Cussatlegras, 2001). Some late-stage phytoplankton blooms may yield a successional accumulation of autotrophic dinoflagellates that may include bioluminescent species, e.g., Lingulodinium sp. (formerly Gonyaulax sp.) or Ceratium fusus, which may also contribute to a positive relationship between chlorophyll $a$ and bioluminescence (Swift et al., 1995; Lapota, 1998). In addition, it has been found that dinoflagellate blooms increased the amounts of luminescent marine snow (Alldredge et al., 1998; Haddock, 1998), which can be a dominant source of bioluminescence (Herren et al., 2003). Likewise, when bioluminescence is high with little fluorescence, traditional interpretations would suggest a dominance of heterotrophic organisms. These assumptions have been shown to be generally valid, given the large differences across coastal ecosystems in the percent of both heterotrophs and autotrophs that are bioluminescent (Lapota, 1998). While this is a common approach for delineating plankton communities, it is difficult to apply objectively across space and time. As the flash kinetics (intensity and duration) differ with size, and size generally delineates between phytoplankton and secondary producers (Fig. 1), we attempted to use the bioluminescence signal intensity as a single measure to identify the coarse structure of the planktonic community. Dinoflagellates generally have a lower flash intensity than zooplankton and, integrated over a large region, are generally more abundant in number and uniform in their distribution. Zooplankton (i.e. copepods), conversely, are fewer in number in an equivalent volume, but have a more intense flash. These differences are hypothesized here to lead to variation in signal outputs from the bathyphotometer.

\subsection{Planktonic communities}

Using the data collected by the REMUS in Monterey Bay in 2002, we compared the average bioluminescence intensity to the square root of variance in signals, or $\mathrm{CV}$, as a way to distinguish these communities. There was, in fact, a distinct bifurcation of the data, with one distribution of points showing a higher CV (slope) than the other grouping of points (Fig. 5). Given the assumptions above, the grouping with high CV was consistent with zooplankton; decreased flash frequency being however more intense. To attempt to validate this hypothesis, the concurrent fluorescence measures were overlaid on the distribution of bioluminescence data (Fig. 5). Fluorescence was grouped with the lower CV signal, suggesting these were either autotrophic dinoflagellates or heterotrophic dinoflagellates associated with autotrophic species. High fluorescence was absent in the high-CV data cluster, suggesting zooplankton. Lapota et al. (1989) demonstrated that 

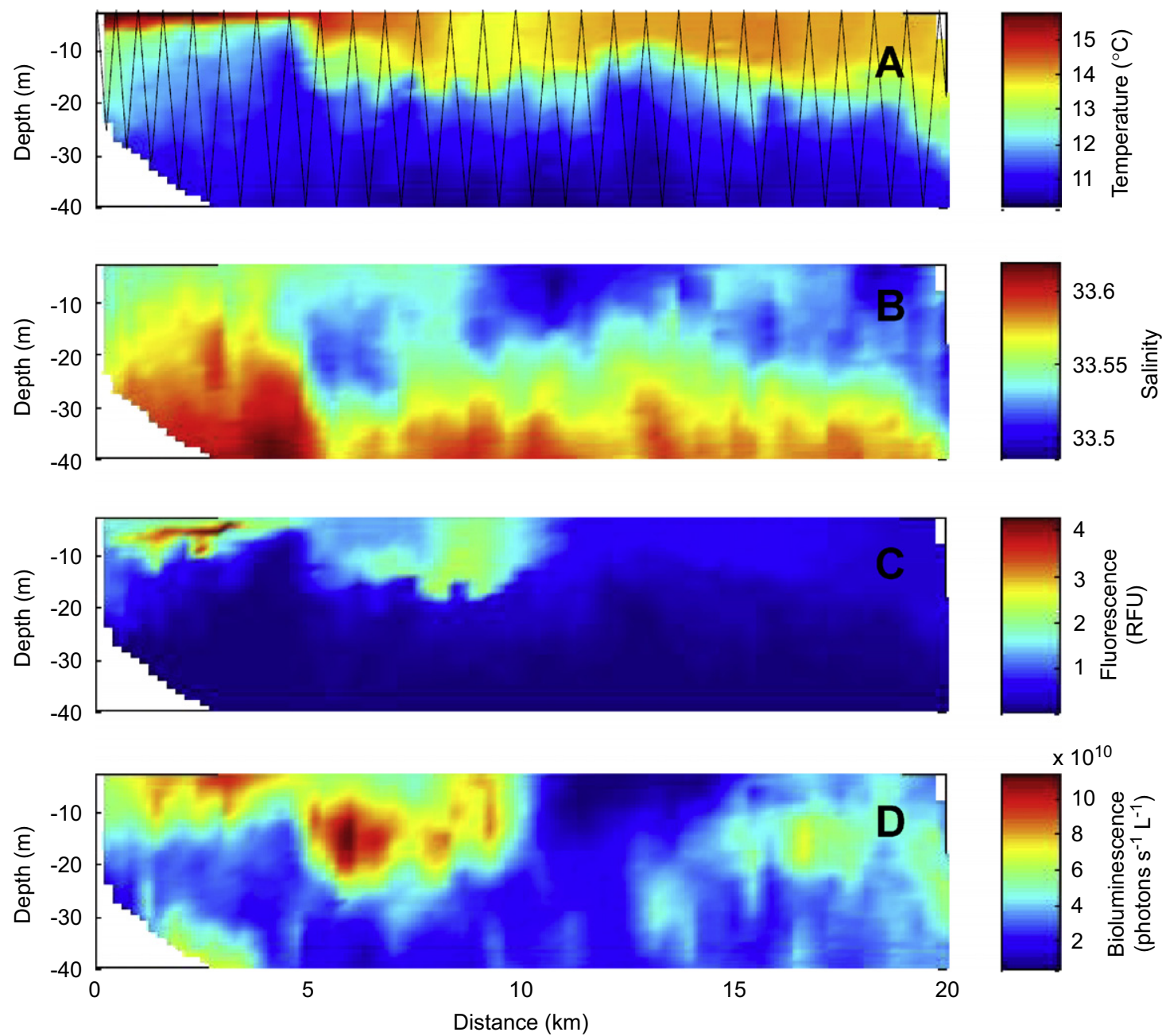

Distance $(\mathrm{km})$

Fig. 4. Depth distributions of (A) temperature $\left({ }^{\circ} \mathrm{C}\right.$ ), (B) salinity, (C) fluorescence (RFU), and (D) bioluminescence (photons s ${ }^{-1} \mathrm{~L}^{-1}$ ) collected by the REMUS vehicle in Monterey Bay along transect line "a" (Fig. 3) on August 20, 2002. Flight path of the REMUS vehicle is shown in (A).

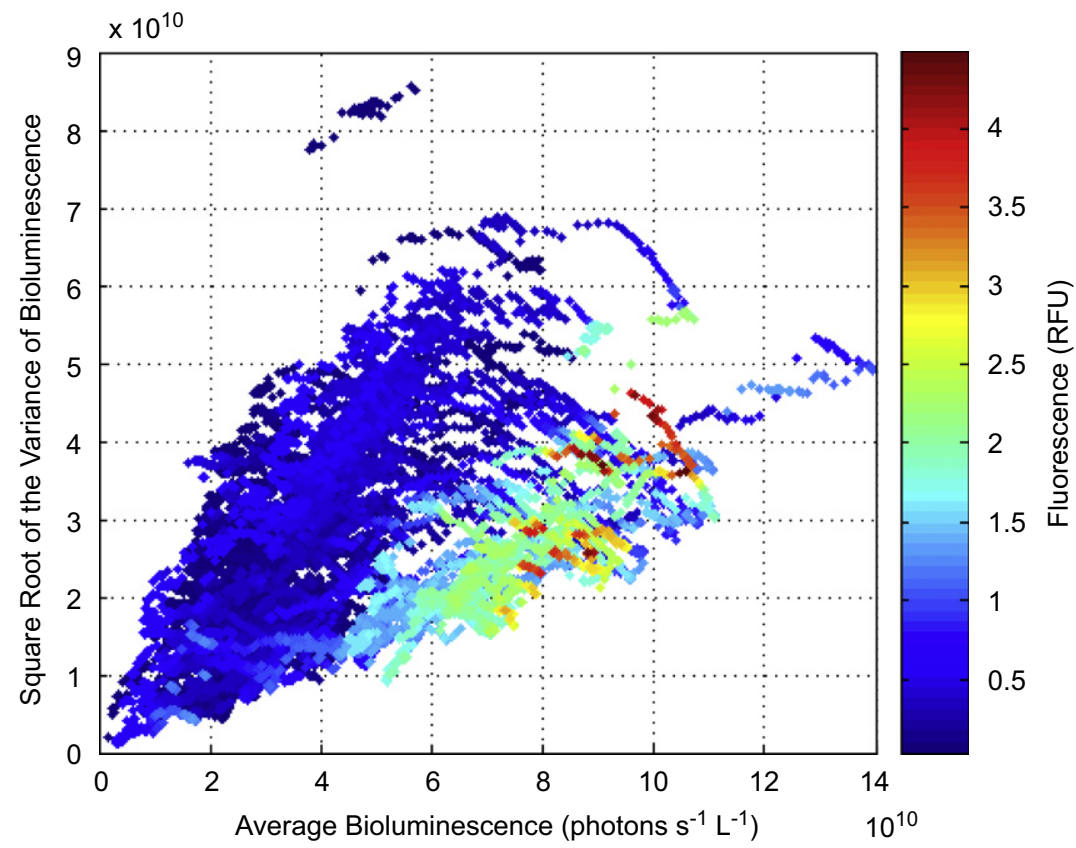

Fig. 5. Average bioluminescence (photons $\mathrm{s}^{-1} \mathrm{~L}^{-1}$ ) as a function of the square root of variance of bioluminescence for data shown in Fig. 4. Variance and average were calculated using a sliding data window of observations, representing $25 \mathrm{~m}$ linear distance. Each observation of bioluminescence is overlaid with the concurrent value of fluorescence (RFU). 
Table 1

Identification and abundance (number $\mathrm{L}^{-1}$ ) of phytoplankton and zooplankton and in samples collected by Schindler trap in Monterey Bay, CA on August 20, 2002 along transect line shown in Fig. 4

\begin{tabular}{|c|c|c|c|c|c|c|c|c|c|c|}
\hline $\begin{array}{l}\text { Distance offshore }(\mathrm{km}) \\
\text { Depth }(\mathrm{m})\end{array}$ & $\begin{array}{l}0.5 \\
6\end{array}$ & $\begin{array}{l}1.0 \\
9\end{array}$ & $\begin{array}{l}1.0 \\
20\end{array}$ & $\begin{array}{l}6.7 \\
9\end{array}$ & $\begin{array}{l}11.9 \\
5\end{array}$ & $\begin{array}{l}11.9 \\
37\end{array}$ & $\begin{array}{l}16.1 \\
7\end{array}$ & $\begin{array}{l}16.1 \\
35\end{array}$ & $\begin{array}{l}21.7 \\
8\end{array}$ & $\begin{array}{l}21.7 \\
35\end{array}$ \\
\hline \multicolumn{11}{|l|}{ Dinoflagellates } \\
\hline \multicolumn{11}{|l|}{ Autotrophic } \\
\hline G. sanguineum & & & & & & & 530 & 240 & & \\
\hline Gymnodinium sp. ${ }^{\mathrm{a}, \mathrm{b}}$ & 10 & 10 & 10 & 30 & & & 350 & 540 & 120 & 120 \\
\hline Ceratium fusus ${ }^{\mathrm{b}}$ & & & & & 20 & 20 & 20 & & & \\
\hline Ceratium sp. ${ }^{\mathrm{b}}$ & 20 & 20 & 20 & & 10 & 10 & 150 & 100 & & \\
\hline Alexandrium cantenella ${ }^{\mathrm{b}}$ & & & & & 20 & 20 & 20 & 120 & & \\
\hline Prorocentrum micans & & 20 & 20 & 20 & 50 & 50 & 310 & 230 & & \\
\hline Prorocentrum sp. ${ }^{\mathrm{b}}$ & 50 & 30 & 30 & & 20 & 20 & 420 & 320 & & \\
\hline Gyrodinium sp. $^{\mathrm{a}}$ & 10 & 10 & 10 & 10 & & & 420 & 10 & & \\
\hline Pyrocystis sp. ${ }^{\mathrm{b}}$ & & & & & & & 130 & 20 & & \\
\hline L. polyedra ${ }^{\mathrm{b}}$ & & & & & & & 220 & 270 & & \\
\hline Oxytoxum sp. & & & & & & & & 40 & & \\
\hline \multicolumn{11}{|l|}{ Heterotrophic } \\
\hline Protoperidinium sp. ${ }^{\mathrm{b}}$ & & & & 130 & & & 160 & 20 & & \\
\hline Polykrikos schwartzii & & & & & & & & 10 & & \\
\hline Noctiluca scintillans ${ }^{\mathrm{b}}$ & & & & & & & 20 & 20 & & \\
\hline Oxyphysis sp. & & & & & & & 30 & & & \\
\hline Dinophysis sp. ${ }^{\mathrm{b}}$ & & & & & & & 10 & 30 & & \\
\hline \multicolumn{11}{|l|}{ Diatoms } \\
\hline Chaetoceros sp. & 10 & & 10 & 10 & 10 & 10 & & 10 & 10 & 10 \\
\hline Eucampia sp. & 10 & & & 10 & 10 & 100 & 10 & 100 & 100 & 10 \\
\hline Pseudonitzschia sp. & 10 & 10 & 100 & 10 & 100 & 1000 & 100 & 1000 & 1000 & 100 \\
\hline Thalassionema sp. & 10 & & 10 & 10 & 10 & 10 & & 10 & 10 & 10 \\
\hline Coscinodiscus sp. & 10 & 10 & 10 & 10 & 10 & 10 & 10 & 10 & 10 & 10 \\
\hline Other & 70 & 30 & 10 & 30 & 30 & 50 & 20 & 70 & 40 & 80 \\
\hline \multicolumn{11}{|l|}{ Zooplankton } \\
\hline Ciliates & 80 & 30 & 30 & 160 & 110 & 110 & 470 & 80 & 70 & 70 \\
\hline Copepod & & & & 10 & 10 & 10 & & & & \\
\hline Copepod Nauplii & 10 & 20 & 20 & & 20 & 20 & 60 & 40 & 20 & 20 \\
\hline Veliger & & & & 10 & & & & 10 & & \\
\hline Pluterus larvae & & & & & & & 10 & & & \\
\hline
\end{tabular}

a Species can be heterotrophic or mixotrophic.

${ }^{\mathrm{b}}$ Bioluminescent or can have bioluminescent species.

even when correlations between fluorescence and bioluminescence are strong, it does not necessarily confirm that the fluorescence has been due to the luminescent organisms as heterotrophic dinoflagellates may often dominate the planktonic community. The plankton collected along the transect clearly showed the majority of phytoplankton cells were diatoms; however, a high fraction of the cells were dinoflagellates and a significant portion of those were bioluminescent (Table 1). Of the bioluminescent fraction, $\sim 70 \%$ were autotrophic. It is clear that all the fluorescence is not related to luminescent organisms with lower CV; however, the amount of fluorescence in this group is higher than seen in the high-CV distribution. Therefore, for this location and time, fluorescence provides some confirmation that the variance in bioluminescence measurements can discriminate between planktonic communities in this data set.

To further validate the use of $\mathrm{CV}$, a number of controlled experiments were conducted. In June 2004, a bathyphotometer was suspended in the water column in San Luis Obispo Bay (Figs. 2 and 3). The bathyphotometer was alternately pre-screened with a $190-\mu \mathrm{m}$ screen to exclude zooplankton or not screened. Microscopic identification of the samples going through the bathyphotometer confirmed this approach (Table 2). The CV of screened bathyphotometer measurements was lower and significantly different than the non-screened condition containing zooplankton community (Fig. 6). This experiment was repeated in triplicate with the same findings. A similar approach was used with the REMUS vehicle in September 2004 to validate the
Table 2

Identification and abundance (number $\mathrm{L}^{-1}$ ) of zooplankton and dinoflagellates in samples collected through the bathyphotometers in San Luis Obispo Bay, CA on June 9, 2004 between 23:45 and 00:31 PDT

\begin{tabular}{|c|c|c|}
\hline & No screen & $190 \mu \mathrm{m}$ prescreen \\
\hline \multicolumn{3}{|l|}{ Zooplankton } \\
\hline \multicolumn{3}{|l|}{ Copepods } \\
\hline Metridia sp. ${ }^{a}$ & $29(18)$ & - \\
\hline Calanoid & $31(11)$ & - \\
\hline Cyclopoid & $4(2)$ & 5 \\
\hline Nauplii & $68(27)$ & $33(9)$ \\
\hline \multicolumn{3}{|l|}{ Other } \\
\hline Siphonophore ${ }^{a}$ & $2(1)$ & - \\
\hline Polychaete & $18(5)$ & $3(3)$ \\
\hline Polychaete larva & $30(16)$ & $22(7)$ \\
\hline Crustacean larva & - & 3 \\
\hline \multicolumn{3}{|l|}{ Dinoflagellates } \\
\hline Alexandrium sp. ${ }^{\mathrm{a}}$ & $600(500)$ & $300(300)$ \\
\hline Ceratium furca $^{\mathrm{a}}$ & $100(100)$ & 0 \\
\hline Dinophysis sp. ${ }^{\mathrm{a}}$ & $100(100)$ & $200(100)$ \\
\hline Gonyaulax sp. ${ }^{\mathrm{a}}$ & $600(200)$ & $700(400)$ \\
\hline Gymnodinium sp. ${ }^{\mathrm{a}}$ & $400(300)$ & 0 \\
\hline Lingulodinium polyedrum ${ }^{\mathrm{a}}$ & 0 & $100(100)$ \\
\hline Protoperidinium $^{\mathrm{a}}$ & $5800(1500)$ & $5100(1800)$ \\
\hline Other & $400(0)$ & 0 \\
\hline
\end{tabular}

Samples were collected from a bathyphotometer unscreened and prescreened with $190 \mathrm{~mm}$ mesh. The numbers are the totals of three replicate samples. Numbers in parenthesis are the subset from one of the trials shown in Fig. 6.

a Bioluminescent or can have bioluminescent species.

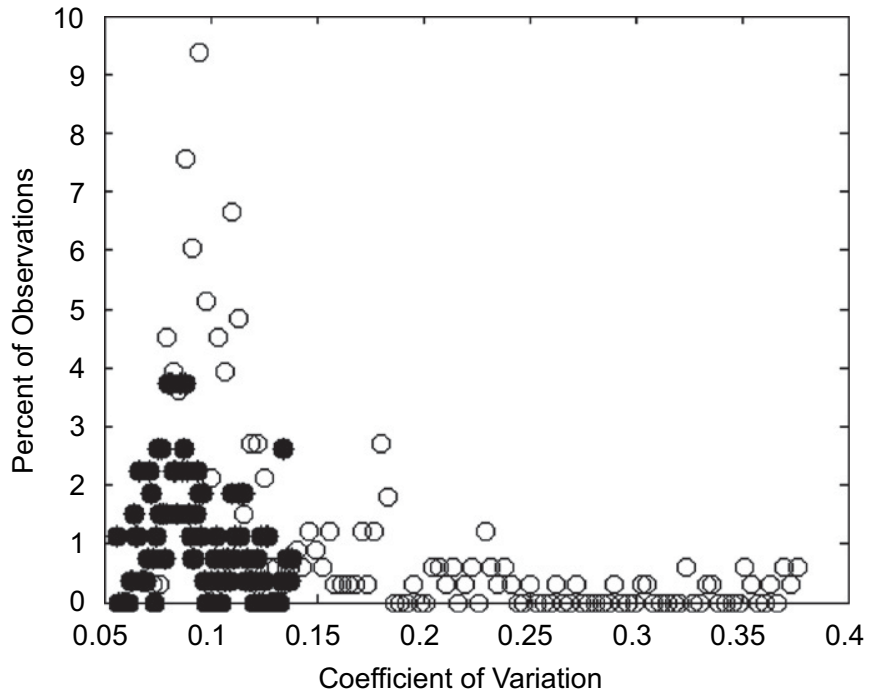

Fig. 6. Coefficient of variation (CV) for bioluminescence made in San Luis Obispo Bay, CA on June 9, 2004 between 23:45 and 00:31 PDT. Variance and average bioluminescence were calculated using a sliding window of 25 measurements or $12.5 \mathrm{~s}$. A bathyphotometer was held at $2.5 \mathrm{~m}$ in the bioluminescence maxima for 3 min. Black circles represent data collected with a $190-\mu \mathrm{m}$ screen in front of intake; white circles had no net covering intake. The ratio is significantly less with $190-\mu \mathrm{m}$ screening covering intake ( $t$-test, $p<0.00, n=599$ ).

approach spatially (Fig. 2C; see Methods). The vehicle went on two identical missions within an hour of each other; one mission with $190-\mu \mathrm{m}$ screen at the water intake and the other without. The vehicle maintained two depths over the mission to sample above and below the thermocline (Fig. 7A). The bioluminescence was almost twofold higher at depth and the difference in BP measured with (Fig. 7B) and without the screen (Fig. 7C) over the intake indicated that signals at depth were generated by organisms larger than $190 \mu \mathrm{m}$. The CV of bioluminescence signal also indicated the presence of zooplankton at depth with a 

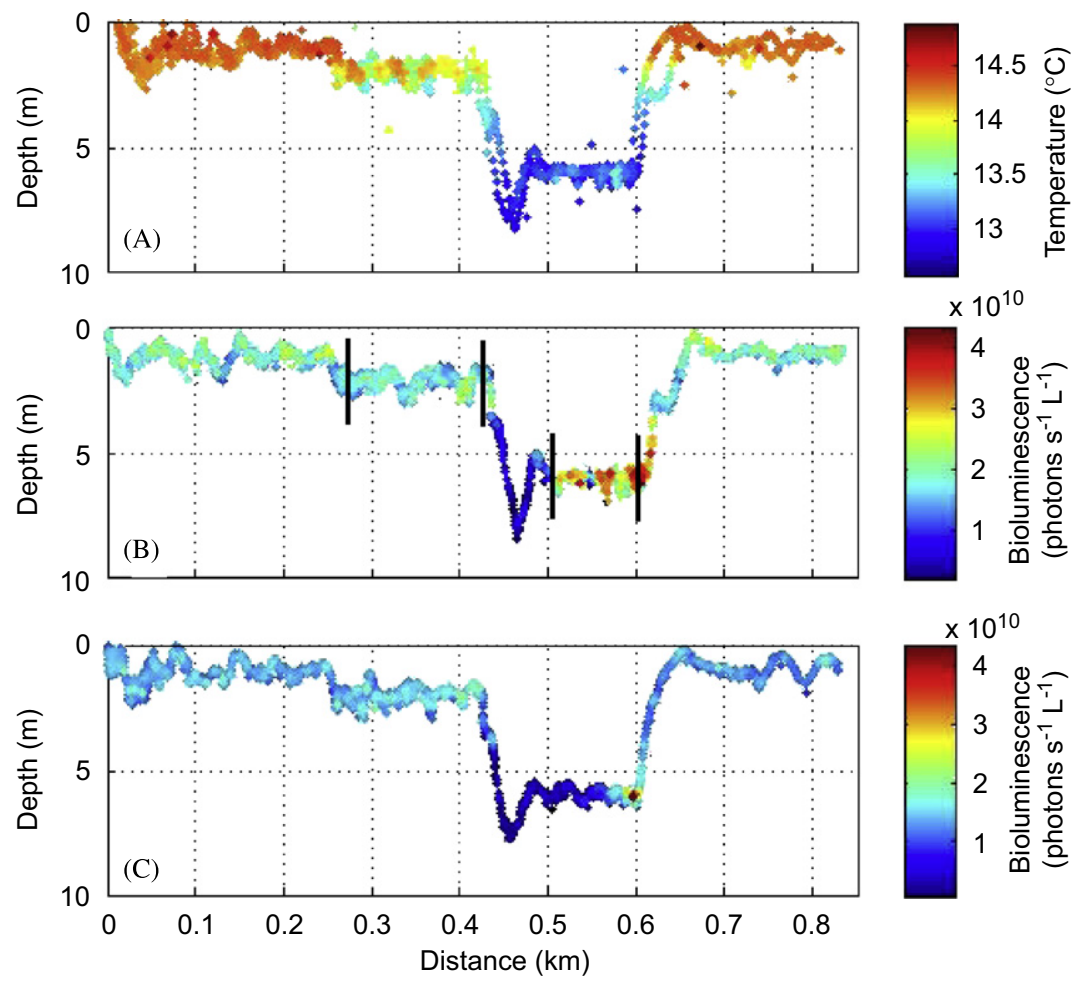

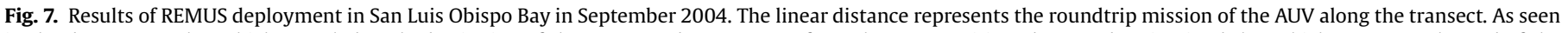

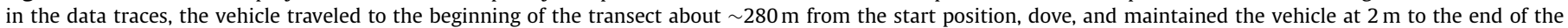
transect. On the return, the vehicle dove and maintained operation at $6 \mathrm{~m}$ until it returned to the beginning of the transect ( $600 \mathrm{~m}$ ), then returned to the start position.

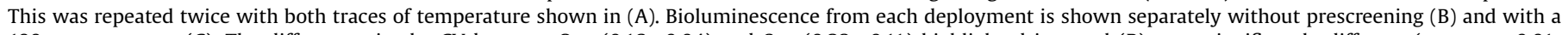

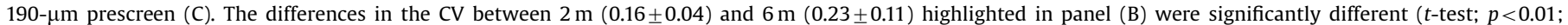
$n=763)$.

significant difference between depths (Fig. 7). Given the validation of this technique with concurrent measures of fluorescence, and temporal and spatial exclusion experiments with screens, we applied the approach to the larger AOSN-II data set.

\subsection{Dynamic structure of planktonic communities}

Data from nine successive nighttime transects across Monterey Bay show spatial differences with depth and distance offshore, as well as time evolution of physical and biological structure of the bay (Fig. 8A). The atmospheric forcing and physical dynamics in this region are well characterized for this time period. The time sequence of data collected by the REMUS catches a slow transition from a strong upwelling event to a relaxation condition (Shulman et al., 2005). Upwelling, affecting the study area, occurred along the coast north of the bay. Upwelled water entered the southern part of the bay and displaced coastal water from north and northeastern sections of the bay, where the sampling took place (Fig. 3). This effectively set up a cyclonic eddy that pushed water onto the coast. This was clear in the temperature data beginning on the fourth night of sampling (August 13, 2004), where the thermocline on both shorelines shallows (Fig. 8A). As time progressed in the sampling, the thermocline deepened on the shore side of transect "a", while remaining relatively shallow on transect "b", consistent with the entrainment of bay water along the upwelling front to the west of transect "a". Fluorescence data showed higher concentrations along the coastline, with significant layering of the phytoplankton community (Fig. 8A). The offshore extent of fluorescence distribution was similar to the data collected in 2002, where higher values were generally restricted to the inner $5 \mathrm{~km}$ along the shelf break (Fig. 4). As time progressed, the depth and offshore extent of fluorescence increased, which is consistent with the physical dynamics. Intermittent high fluorescence was evident in the center of the bay extending to $30 \mathrm{~m}$, and corresponded to the deepening of the thermocline.

Bioluminescence distributions and dynamics showed similarities with fluorescence, with peak values of $2.3 \times 10^{10}$ photons $\mathrm{s}^{-1} \mathrm{~L}^{-1}$ along the shoreline (Fig. 8B). The temporal pattern of entrainment into the upwelling front was also evident along transect "a", with the BP signal deepening and extending from 5 to $10 \mathrm{~km}$ offshore. The bioluminescent communities in the northeast appeared concentrated along the coast during this process when compared to the initial condition, where the communities extended $\sim 10 \mathrm{~km}$ offshore. There was high BP from 20 to $40 \mathrm{~m}$ in the center of the bay, extending inshore at the beginning of the experiment with the highest signal below the thermocline and fluorescence layer. While there were high BP signals in the center of the bay during the entire study, their distribution and intensity changed significantly. Most evident was the apparent separation between the nearshore surface BP signals and the deeper signals in the middle of the bay as the upwelling intensified. This was perhaps due to the intensification of the eddy, as suggested by the vertical distribution of $\mathrm{BP}$, and to some degree fluorescence, on the last two sampling days (Figs. 8A and $\mathrm{B}$ ) and the strength of the eddy (Shulman et al., 2005). The oscillations in depth distributions of the physical and biological parameters, for example inshore on transect "a" on the last night, are consistent with internal waves known to persist in this area (Petruncio et al., 1998).

The depth distribution of $\mathrm{CV}$ of the bioluminescence signal during the AOSN-II experiment is consistent with the dynamics described above, with low CV indicative of dinoflagellates, 

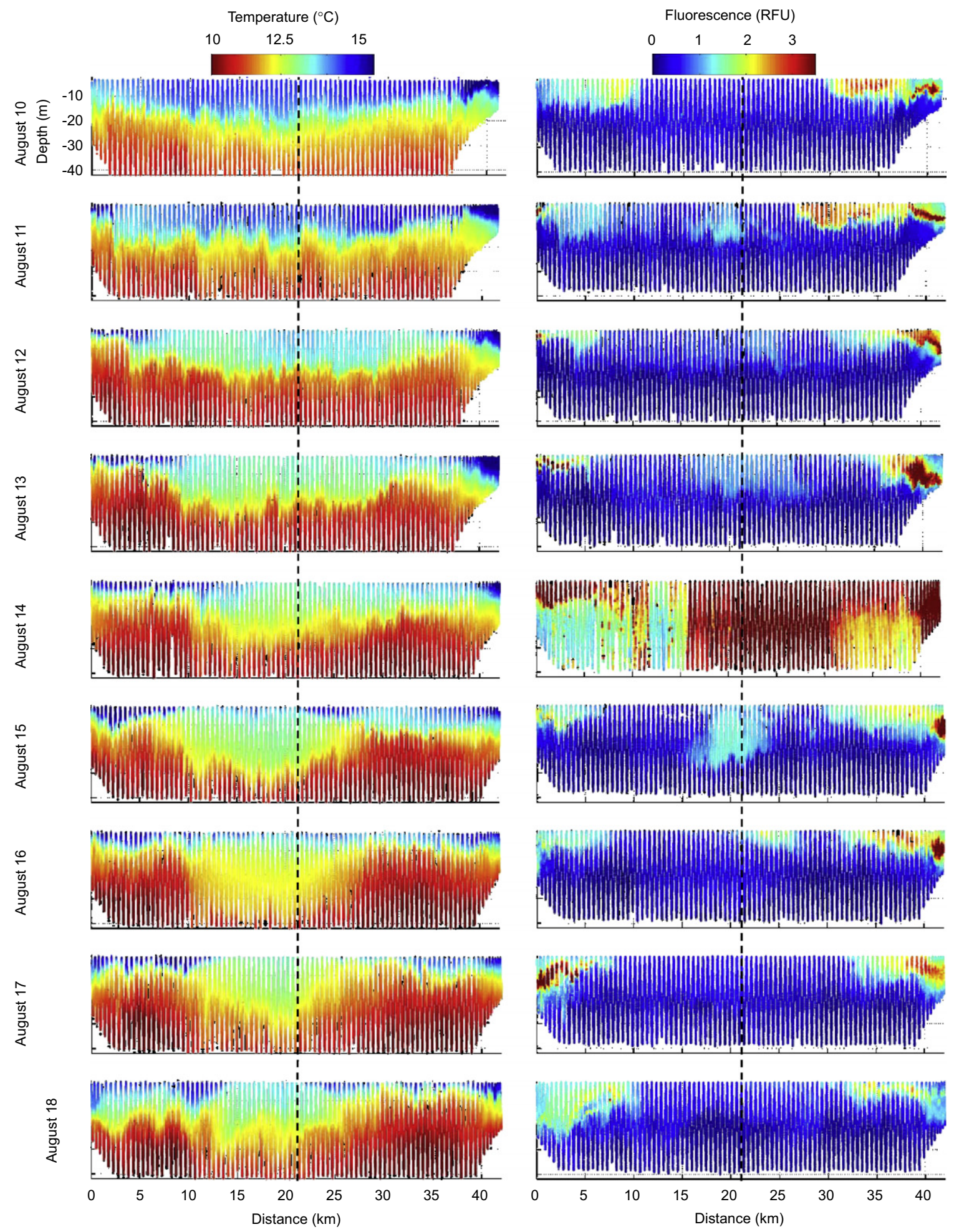

Fig. 8A. Depth distributions of temperature and fluorescence collected by the REMUS AUV along the "a" and "b" transect lines in Monterey Bay (see Fig. 3 ) on nine

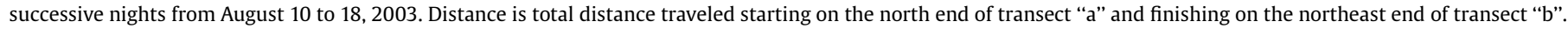

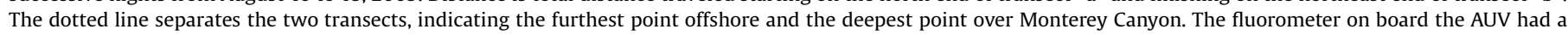
poor connection with the vehicle during the night of August 14, 2006. It is included as some of the coastal features are still evident.

restricted primarily to the coast and corresponding to regions of high fluorescence. The highest $\mathrm{CV}$ values were either below high fluorescent areas nearshore at the beginning of the experiment or distributed throughout the center of the bay and the thermocline interface. What was also clear in CV distribution was the gradual separation of nearshore communities from those in the center of the bay. While CV remained high under the nearshore fluorescence, it decreased in the center of the bay as the distribution of bioluminescent organisms became more uniformly distributed both vertically and horizontally, decreasing the variance in the signal. Whether the separation between nearshore and bay communities was simply displacement driven primarily by the 

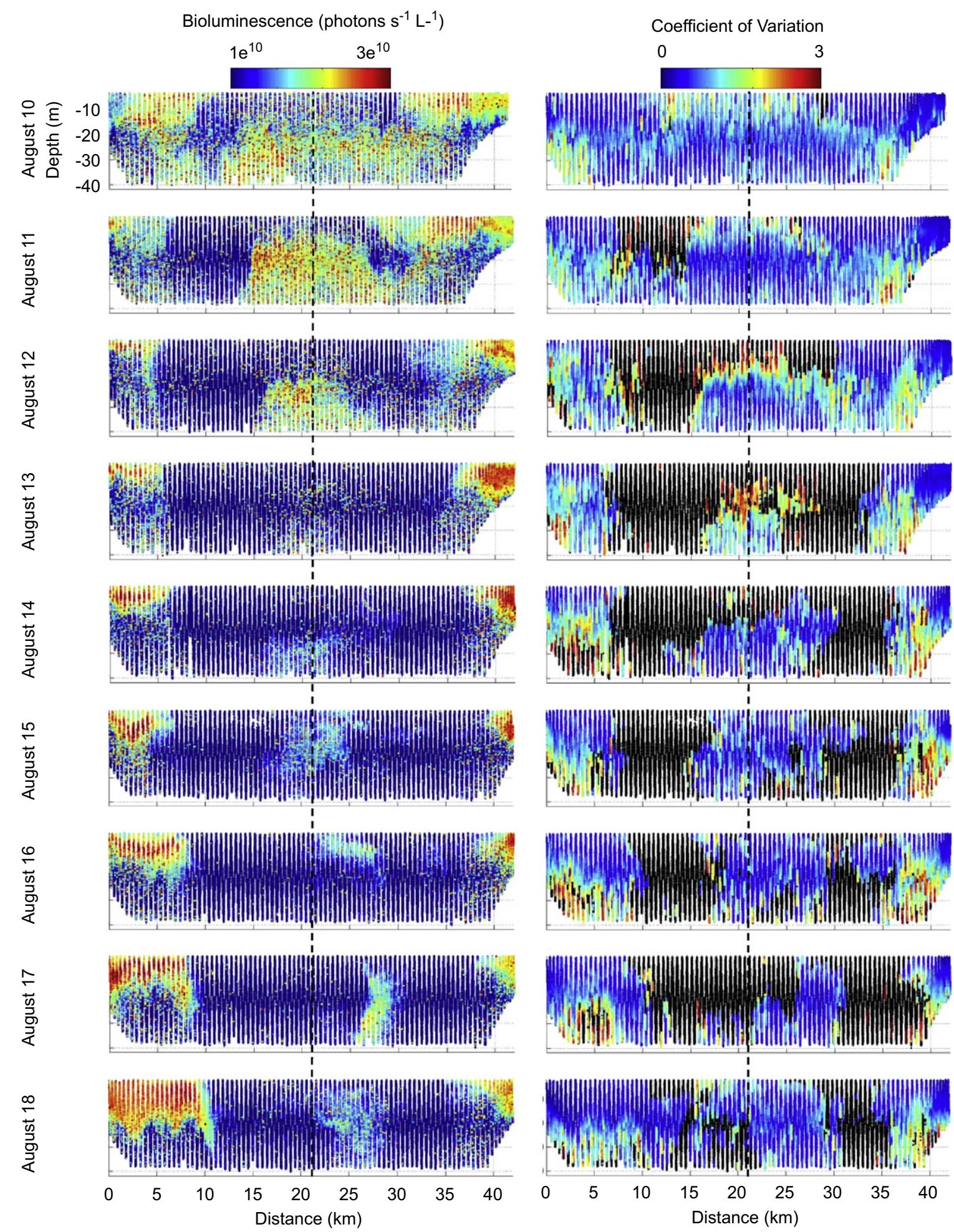

Fig. 8B. Same as $8 \mathrm{~A}$ except with bioluminescence and coefficient of variation (CV). CV was not calculated where the average bioluminescence was less than $5 \times 10^{9}$ photons $\mathrm{S}^{-1} \mathrm{~L}^{-1}$ (black).

circulation pattern or by behavior, it is clear that the potential for coupling and trophic interaction decreased as the upwelling intensified. Using this approach for separating dinoflagellates and zooplankton, the total BP over the 9 days was proportioned as $66 \%$ and $34 \%$, respectively, similar to previous findings (Lapota et al., 1988; Swift et al., 1995).

\subsection{Applications}

There are several scenarios where the application of CV and its interpretation could be difficult. First, as CV is a ratio, the average bioluminescence signal needs to be sufficiently above the background measured by the instrument as evident in Fig. 8B. Second, 

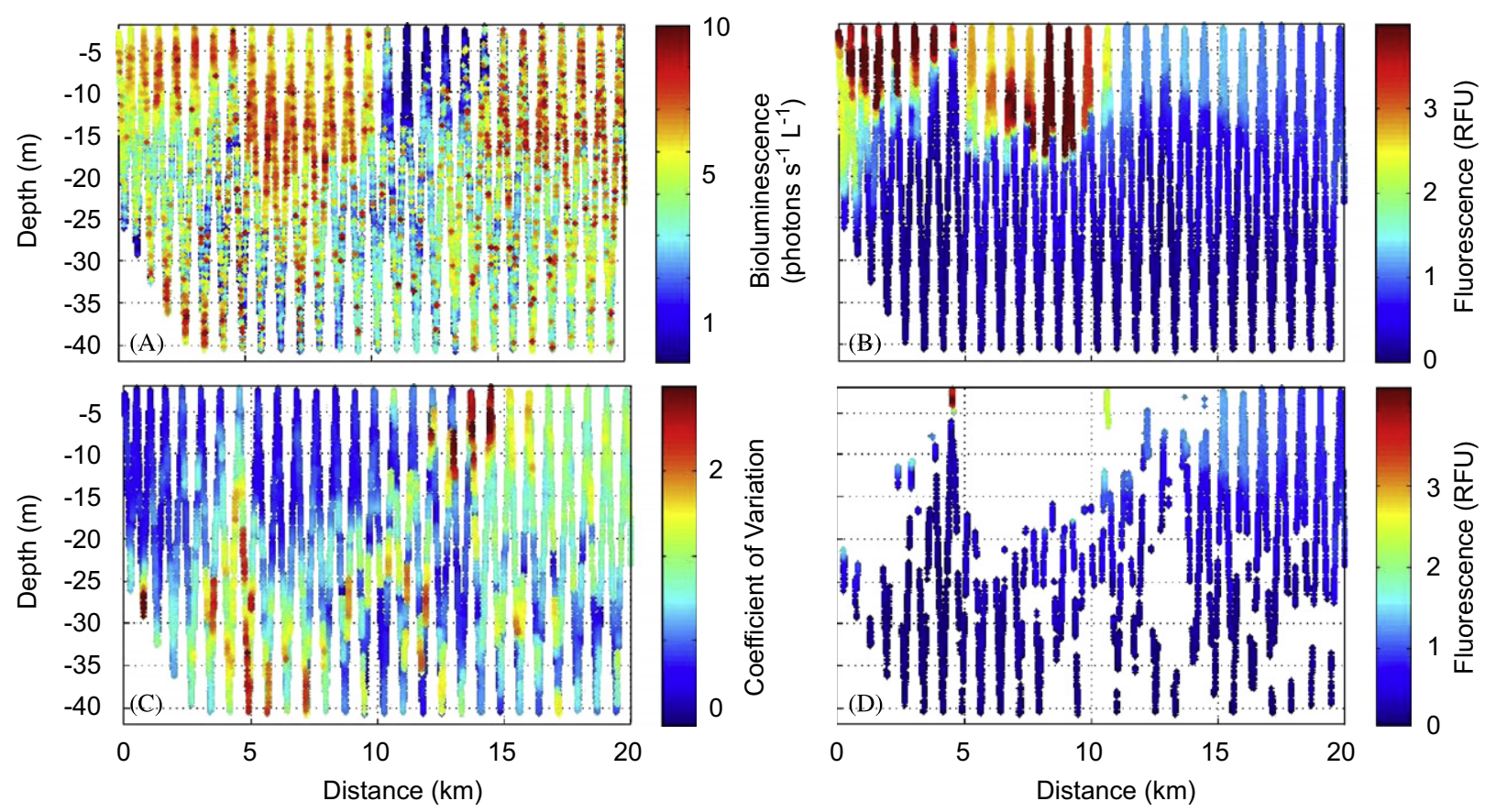

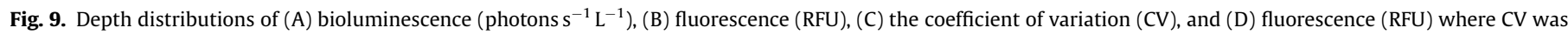
greater than 0.6 collected by the AUV along the "a" transect in Monterey Bay on August 20, 2002.

although not apparent in these data, if the communities are thoroughly mixed the ratio will not be able to differentiate between groups. In addition, some dinoflagellate species can be mixotrophic or heterotrophic, but exhibit the same spatial distributions and flash kinetics as autotrophic dinoflagellates (Lapota et al., 1988), making the application of CV as an absolute method of delineating trophic status of a community problematic. Third, the percent of a given phytoplankton or zooplankton community that is bioluminescent has been shown to vary significantly in time and space (Lapota, 1998), making CV as a quantitative measure that is universally applicable improbable. Lastly, like the measure of apparent optical properties (i.e. irradiance) restricting sampling during daylight hours, bioluminescence requires sampling at night. As shown here, despite these real limitations, this single measure in different coastal regions and at different times of the year may provide qualitative and in some cases quantitative separation between dinoflagellates and zooplankton.

Rapid delineation of these groups in the field could serve to significantly advance the integration of biology into dynamic ocean models. Data-assimilative hindcast/forecast and nowcast models are beginning to couple simple biological models that depend on time and space knowledge of growth and loss terms between bulk communities (i.e. phytoplankton, zooplankton) and assumptions on rates of remineralization (McGillicuddy et al., 1995a,b; Chai et al., 2003; Shulman et al., 2005). In order to advance these model approaches, systematic measures of the modeled quantities and their spatial and temporal scales of distributions are needed for initialization and model validation. Chlorophyll fluorescence and acoustics have been used to validate phytoplankton and zooplankton distributions, respectively; however, there is presently no straightforward single measurement to accomplish this over large domains. This study identifies a potential biological measurement that can be made on the space (kilometers) and time (days) scales relevant for model data assimilation. As with formulating oceanographic models, the upstream conditions need to be considered when defining boundary conditions. This is known for the physical domain, but is also true, and most likely different, for the biological community structure in a regional context.

\subsection{Planktonic interaction}

In addition to discriminate between planktonic communities, data collected in 2002 suggest that this approach has potential to address the interaction of the two groups. As evident in Fig. 5, there was a distinct low but slightly elevated fluorescence signal in the high-CV cluster attributed to zooplankton. Two probable conditions could account for this data distribution. The first possibility is that the zooplankton were mixed with low phytoplankton biomass. However, this appears unlikely because the signal was uniform with no elevated fluorescence values in the high-CV data grouping. Additionally, there was a clear separation in fluorescence, with little to no fluorescence signal between the two CV distributions (Fig. 5). The second possible explanation is that the fluorometer on board the REMUS AUV was detecting fluorescence from the zooplankton guts. Zooplankton gut fluorescence has been a standard measurement for quantifying ingestion, grazing, growth, and fecundity in copepods and gelatinous zooplankton in both lab and field settings (Mackas and Bohrer, 1976; Baars and Oosterhuis, 1984; Dam et al., 1994; Pasternak, 1994; Atkinson et al., 1996; Landry et al., 1997; Harris et al., 2000). Jaffe et al. (1998) and Franks and Jaffe (2001, 2008) simultaneously imaged phytoplankton and zooplankton using a fluorescence-imaging system and identified fluorescing zooplankton guts in situ. It follows, therefore, that a portion of in situ fluorescence measurement would be attributable to zooplankton gut fluorescence, with that contribution varying based on the level of trophic interaction and grazing. A systematic method of separating the fluorescence of living phytoplankton from zooplankton guts, however, has not been identified. The depth distribution of the 2002 fluorescence data from the high-CV data (Fig. 5) showed a pattern supportive of fluorescence being 

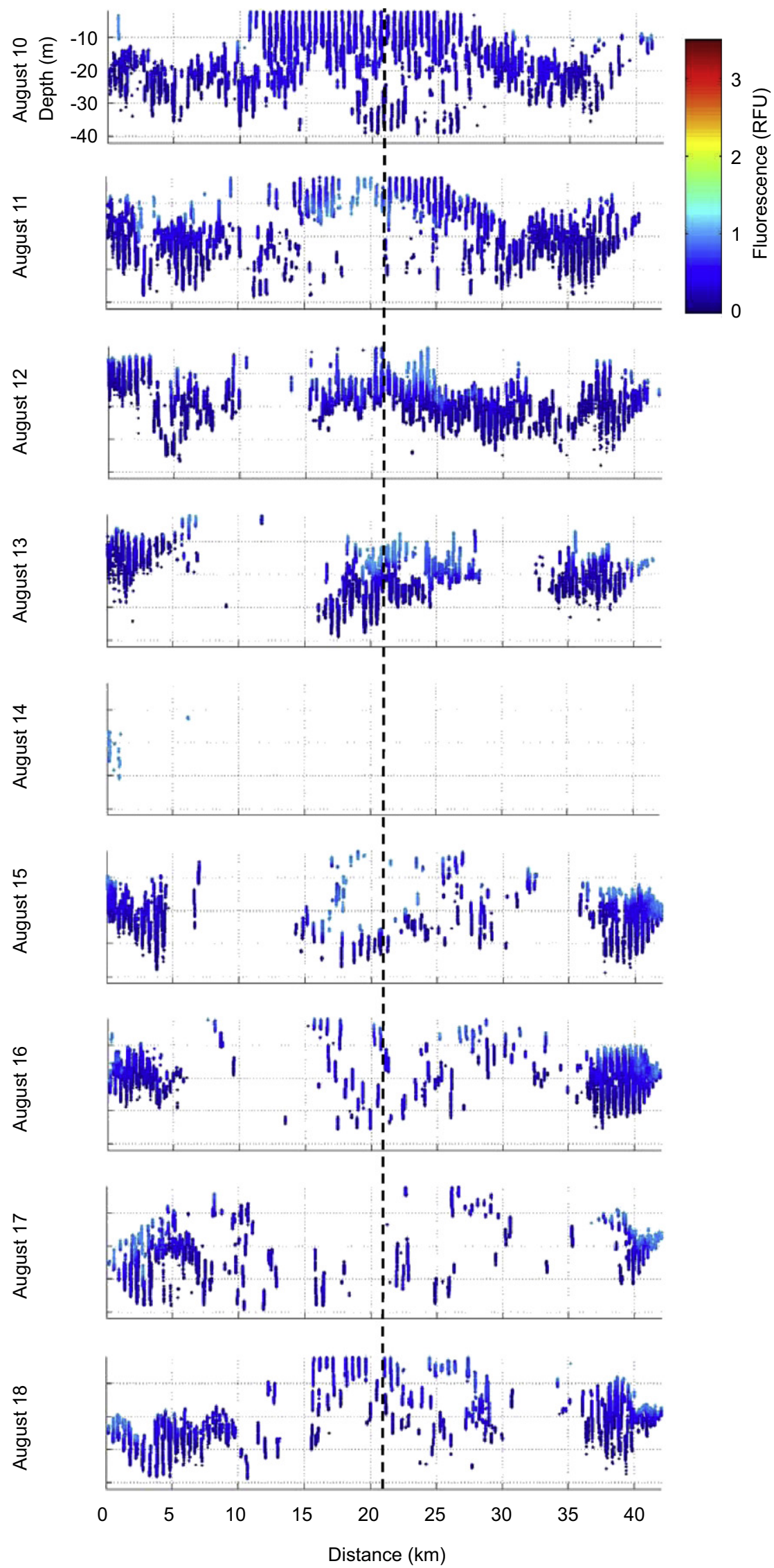

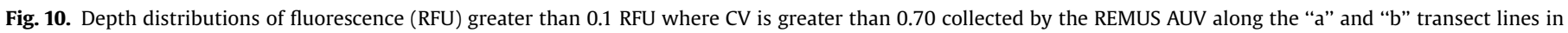

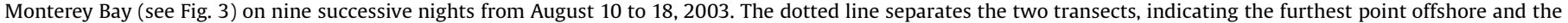

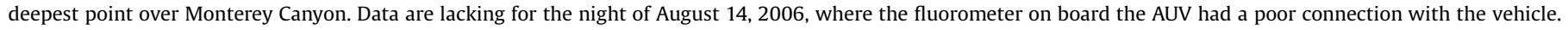


attributed to gut contents of the zooplankton (Fig. 9). The distribution of these data framed the nearshore autotrophic community from both the bottom and vertical fluorescence front $10 \mathrm{~km}$ offshore. Four percent of the total fluorescence along the transect was found to be associated with the zooplankton CV signal.

This finding has a number of significant implications. Fluorescence is used by the oceanographic community as a bulk measure of phytoplankton biomass and subsequently used in estimates of primary production. If a significant fraction of this biomass was actually in zooplankton guts and no longer viable for carbon fixation, there would be an overestimation of carbon productivity. Additionally, these interactions are not distributed uniformly in the water column, leading to further complexity in application. Fig. 10 illustrates this further when the approach is applied to the AOSN-II data set from Monterey Bay. As with the distribution of $\mathrm{CV}$ (Fig. 8B), it is clear that initially there was connectivity in grazing between the coast and the center of the bay. As the eddy intensified, the coastal zooplankton separated from those in the center of the bay and developed distinct regions of trophic transfer. By the last sampling night (into the relaxation period), there is some indication of the grazing connectivity returning. In a modeling context, delineating these fields has the potential to advance coupled physical-biological models and refine the space and time scales of trophic interactions, carbon transfer, and rates of biogeochemical cycling. Although controlled experiments are clearly needed to fully validate the ability to discriminate zooplankton gut fluorescence from viable phytoplankton biomass, results from this study suggest that the combined measurement of bioluminescence and fluorescence may be used to delineate regions of trophic interaction.

\section{Conclusions}

This study takes advantage of the general differences in bioluminescence flash kinetics between dinoflagellates and zooplankton to measure the relative abundances of the two groups within the same time space volume. Results demonstrate this as an approach for distinguishing these general classifications using a single sensor, which was validated in this study using fluorescence and exclusion experiments. Applied to large field data sets, this approach has the potential to provide models with distributions of these planktonic communities for initialization and validation leading to mechanisms governing the patch distribution, coherence, and their biological interactions. The organismal diversity and variability represented in the measure of bioluminescence at a given time and place prevents this approach from being quantitatively applied universally, but may be useful on relatively short time and space scales. Despite these limitations, the measure of BP may afford the oceanographic community a complimentary tool to observe and understand planktonic communities in the ocean.

\section{Acknowledgements}

We thank a number of former graduate students (Jessica Connolly, Ian Robbins, Michael Sauer) and undergraduate students (Jeff Sevadjian, Carol Boland) for their help in sample collection and AUV deployments. We would also like to thank Cyril Johnson for instrument calibration and design, and the crew of R/V Paragon (UCSC) and the AOSN-II team for their logistical support. This work was supported by the Office of Naval Research (N00014-00-1-0570 and N00014-03-1-0341 to M. Moline).

\section{References}

Abrahams, V.A., Townsend, L.D., 1993. Bioluminescence in dinoflagellates: a test of the burglar alarm hypothesis. Ecology 74, 258-260.

Alberte, R.S., 1993. Bioluminescence: the fascination, phenomena, and fundamentals. Naval Research Reviews 45, 2-12.

Alldredge, A.L., Passow, U., Haddock, S.H.D., 1998. The characteristics and transparent exopolymer particle (TEP) content of marine snow formed from thecate dinoflagellates. Journal of Plankton Research 20, 393-406.

Atkinson, A., Shreeve, R.S., Pakhomov, E.A., Priddle, J., Blight, S.P., Ward, P., 1996. Zooplankton response to a phytoplankton bloom near South Georgia, Antarctica. Marine Ecology Progress Series 144, 195-210.

Baars, M.A., Oosterhuis, S.S., 1984. Diurnal feeding rhythms in North Sea copepods measured by gut fluorescence, digestive enzyme activity and grazing on labeled food. Netherlands Journal of Sea Research 8, 97-119.

Batchelder, H.P., Swift, E., 1989. Estimated near-surface mesoplanktonic bioluminescence in the western North Atlantic during July 1986. Limnology and Oceanography 34, 113-128.

Batchelder, H.P., Swift, E., van Keuren, J.R., 1990. Pattern of planktonic bioluminescence in the northern Sargasso Sea: seasonal and vertical distribution. Marine Biology 104, 153-164.

Batchelder, H.P., Swift, E., van Keuren, J.R., 1992. Diel patterns of planktonic bioluminescence in the northern Sargasso Sea. Marine Biology 113, 329-339.

Benoit-Bird, K.J., Au, W.W.L., 2003. Echo strength and density structure of Hawaiian mesopelagic boundary community patches. Journal of the Acoustical Society of America 114, 1888-1897.

Blackwell, S.M., 2002. A new platform for studying bioluminescence in the coastal ocean. M.S. Thesis, California Polytechnic State University, California, USA, unpublished.

Blackwell, S.M., Moline, M.A., Schaffner, A., Chang, G., 2007. Sub-kilometer length scales of physical and biological parameters in coastal waters. Continental Shelf Research 28, 215-226.

Burkenroad, M.D., 1943. A possible function of bioluminescence. Journal of Marine Research 5, 161-164.

Case, J.F., Widder, E.A., Bernsein, S., Ferer, K., Young, D., Latz, M.I., Geiger, M., Lapota, D., 1993. Assessment of marine bioluminescence. Naval Research Reviews 45 31-41.

Chai, F., Jiang, M., Barber, R.T., Dugdale, R.C., Chao, Y., 2003. Interdecadal CViation of the transition zone chlorophyll front, a physical-biological model simulation between 1960 and 1990. Journal of Oceanography 59, 461-475.

Clarke, G.L., Kelley, M.G., 1965. Measurements of diurnal changes in bioluminescence from the sea surface to 2,000 meters using a new photometric device. Limnology and Oceanography 10, 54-66.

Clarke, G.L., Wertheim, G.K., 1956. Measurements of illumination at great depths and at night in the Atlantic Ocean by means of a new bathyphotometer. DeepSea Research 3, 189-205.

Cochrane, N.A., Sameoto, D.D., Herman, A.W., 2000. Scotian Shelf euphausiid and silver hake population changes during 1984-1996 measured by multifrequency acoustics. Journal of Marine Science 57, 122-132.

Dam, H.G., Peterson, W.T., Bellantoni, D.C., 1994. Seasonal feeding and fecundity of the calanoid copepod Acartia tonsa in Long Island Sound: is omnivory important to egg production? Hydrobiologia 292/293, 191-199.

Deutschman, D.H., Bradshaw, G.A., Childress, W.M., Daly, K.L., Grunbaum, D., Pascual, M., Schumaker, N., Wu, J., 1993. Mechanisms of patch formation. In: Levin, S., Powell, T., Steele, J. (Eds.), Patch Dynamics. Lecture Notes in Biomathematics, vol. 96. Springer, Berlin, pp. 184-208.

Ducklow, H.W., McCallister, S.L., 2005. The biogeochemistry of carbon dioxide in the coastal oceans. In: Robinson, A.R., Brink, K.H. (Eds.), The Global Coasta Ocean Multiscale Interdisciplinary Processes. The Sea, vol. 13. Harvard University Press, Cambridge, MA, pp. 269-315.

Flagg, C.N., Smith, S.L., 1989. On the use of the acoustic doppler current profiler to measure zooplankton abundance. Deep-Sea Research 36, 455-474.

Franks, P.J.S., Jaffe, J.S., 2001. Microscale distributions of phytoplankton: initial results from a two-dimensional imaging fluorometer, OSST. Marine Ecology Progress Series 220, 59-72.

Franks, P.J.S., Jaffe, J.S., 2008. Microscale variability in the distributions of large fluorescent particles observed in situ with a planar laser imaging fluorometer. Journal of Marine Systems 69, 254-270.

Geistdoerfer, P., Cussatlegras, A.-S., 2001. nycthémérales de la bioluminescence marine en Méditerranée et dans l'Atlantique nord-est. Comptes Rendus de l'Académie des Sciences 324, 1037-1044.

Haddock, S.H.D., 1998. Bioluminescence in the deep-sea and open ocean: gelatinous zooplankton and marine snow. Ph.D. Thesis, University of California, Santa Barbara, USA, unpublished.

Haddock, S.H.D., Case, J.F., 1999. Bioluminescence spectra of shallow and deep-sea gelatinous zooplankton: ctenophores, medusae and siphonophores. Marine Biology 133, 571-582.

Haddock, S.H.D., Rivers, T.J., Robison, B.H., 2001. Can coelenterates make coelenterazine? Dietary requirement for luciferin in cnidarian bioluminescence. Proceedings of the National Academy of Sciences of the United States of America 98, 11148-11151.

Hall, S.J., Raffaelli, D.G., 1993. Food webs: theory and reality. Advances in Ecological Research 24, 187-239.

Harris, R., Wiebe, P., Lenz, J., Skjoldal, H-R., Huntley, M., 2000. ICES Zooplankton Methodology Manual. Academic Press, London, p. 684. 
Herren, C.M., Alldredge, A.L., Case, J.F., 2003. Coastal bioluminescent marine snow: fine structure of bioluminescence distribution. Continental Shelf Research 24 413-442.

Herren, C.M., Haddock, S.H.D., Johnson, C., Orrico, C.M., Moline, M.A., Case, J.F., 2005. A multi-platform bathyphotometer for fine-scale, coastal bioluminescence research. Limnology and Oceanography: Methods 3, 247-262.

Herring, P.J., 1987. Systematic distribution of bioluminescence in living organisms. Journal of Bioluminescence and Chemiluminescence 1, 147-163.

Holliday, D.V., Pieper, R.E., 1980. Volume scattering strengths and zooplankton distributions at acoustic frequencies between 0.5 and $3 \mathrm{MHz}$. Journal of the Acoustical Society of America 67, 135-146.

Holliday, D.V., Pieper, R.E., Kleppel, G.S., 1989. Determination of zooplankton size and distribution with multi-frequency acoustic technology. Journal of the International Council for the Exploration of the Sea 41, 226-238.

Holligan, P.M., Reiners, W.A., 1992. Predicting the responses of the coastal zone to global change. Advances in Ecological Research 22, 211-255.

Jaffe, J.S., Franks, P.J.S., Leising, A.W., 1998. Simultaneous imaging of phytoplankton and zooplankton distributions. Oceanography 11, 1-5.

Jahnke, R.A., 2005. Transport processes and organic matter cycling in coasta sediments. In: Robinson, A.R., Brink, K.H. (Eds.), The Global Coastal Ocean Multiscale Interdisciplinary Processes. The Sea, vol. 13. Harvard University Press, Cambridge, MA, pp. 163-191.

Johnson, C.H., Knight, M., Trewavas, A., Kondo, T., 1998. A clockwork green: circadian programs in photosynthetic organisms. In: Lumsden, P., Millar, A (Eds.), Biological Rhythms and Photoperiodism in Plants. BIOS Scientific Publishers, Oxford, pp. 1-34

Johnson, W.S., Allen, D.M. (Eds.), 2005. Zooplankton of the Atlantic and Gulf Coasts: A Guide to Their Identification and Ecology. Johns Hopkins Press, Baltimore, p. 365.

Johnson, W.W., 1948. Sound as a tool in marine ecology, from data on biologica noises and the deep scattering layer. Journal of Marine Research 7, 443-458.

Kantha, L.H., Clayson, C.A. (Eds.), 2000. Small Scale Processes in Geophysical Flows. Academic Press, London, p. 888.

Kirkpatrick, G.J., Schofield, O., Millie, D.F., Moline, M.A., 2000. Optical discrimination of a phytoplankton species in natural mixed populations. Limnology and Oceanography 45, 467-471.

Landry, M.R., Barber, R.T., Bidigare, R.R., Chai, F., Coale, K.H., Dam, H.G., Lewis, M.R. Lindley, S.T., McCarthey, J.J., Roman, M.R., Stoecker, D.K., Verity, P.G., White, J.R. 1997. Iron and grazing constraints on primary production in the Centra Equatorial Pacific: an EqPac synthesis. Limnology and Oceanography 42 405-418.

Lapota, D., 1998. Long term and seasonal changes in dinoflagellate bioluminescence in the Southern California Bight. Ph.D. Thesis, University of California, Santa Barbara, USA, unpublished.

Lapota, D., Losee, J.R., 1984. Observations of bioluminescence in marine plankton from the Sea of Cortez. Journal of Experimental Marine Biology and Ecology 77, 209-240.

Lapota, D., Galt, C., Losee, J., Huddell, H.D., Orzech, J.K., Nealson, K.H., 1988 Observations and measurements of planktonic bioluminescence in and around a milky sea. Journal of Experimental Marine Biology and Ecology 119, 55-81.

Lapota, D., Geiger, M.L., Stiffey, A.V., Rosenberger, D.E., Young, D.K., 1989. Correlation of planktonic bioluminescence with other oceanographic parameters from a Norwegian fjord. Marine Ecology Progress Series 55, 217-228.

Lapota, D., Rosenberger, D.E., Lieberman, S.H., 1992. Planktonic bioluminescence in the pack ice and the marginal ice zone of the Beaufort Sea. Marine Biology 112, 665-675.

Latz, M.I., Frank, T.M., Case, J.F., 1988. Spectral composition of bioluminescence of epipelagic organisms from the Sargasso Sea. Marine Biology 98, 441-446.

Levin, S.A., 1992. The problem of pattern and scale in ecology. Ecology 73 1943-1967.

Lieberman, S.H., Lapota, D., Losee, J., Zirino, A., 1987. Planktonic bioluminescence in the surface waters of the Gulf of California. Biological Oceanography 4, 25-46.

Lorenzen, C.J., 1966. A method of the continuous measurement of in vivo Chlorophyll concentration. Deep-Sea Research 13, 223-227.

Losee, J., Richter, K., Lieberman, S., Lapota, D., 1989. Bioluminescence: spatial statistics in the North Atlantic. Deep-Sea Research 36, 783-801.

Mackas, D., Bohrer, R., 1976. Fluorescence analysis of zooplankton gut contents and an investigation of diel feeding patterns. Journal of Experimental Marine Biology and Ecology 25, 77-85.
McGillicuddy, D.J., McCarthy, J.J., Robinson, A.R., 1995a. Coupled physical and biological modeling of the spring bloom in the North Atlantic: I. Model formulation and one dimensional bloom processes. Deep-Sea Research I 42 1313-1357.

McGillicuddy, D.J., Robinson, A.R., McCarthy, J.J., 1995b. Coupled physical and biological modeling of the spring bloom in the North Atlantic: II. Three dimensional bloom and post-bloom processes. Deep-Sea Research I 42 1359-1398.

Moline, M.A., Heine, E., Case, J., Herren, C., Schofield, O., 2001. Spatial and temporal CViability of bioluminescence potential in coastal regions. In: Case, J.F. Herring, P.J., Haddock, S.H.D., Kricka, L.J., Stanley, P.E. (Eds.), Bioluminescence and Chemiluminescence 2000. World Scientific Publishing Company, Singapore, pp. 123-126.

Moline, M.A., Blackwell, S.M., Von Alt, C., Allen, B., Austin, T., Case, J., Forrester, N. Goldsborough, R., Purcell, M., Stokey, R., 2005. Remote environmental monitoring units: an autonomous vehicle for characterizing coastal environments. Journal of Atmospheric and Oceanic Technology 22, 1797-1808.

Moore, C., 1994. Spectral absorption, attenuation, fluorescence meters-a new window of opportunity for ocean scientists. Sea Technology 35, 10-16.

Morin, J.G., 1983. Coastal bioluminescence: patterns and functions. Bulletin of Marine Science 33, 787-817.

Morin, J.G., Cohen, A.C., 1991. Bioluminescent displays, courtship, and reproduction in ostracodes. In: Bauer, R., Martin, J. (Eds.), Crustacean Sexual Biology. Columbia University Press, New York, pp. 1-16.

Morse, D., Milos, P.M., Roux, E., Hastings, JW. 1989. Circadian regulation of the synthesis of substrate binding protein in the Gonyaulax bioluminescent system involves translational control. Proceedings of the National Academy of Sciences of the United States of America 86, 172-176.

Pasternak, A.F., 1994. Gut fluorescence in herbivorous copepods: an attempt to justify the method. Hydrobiologia 292/293, 241-248.

Petruncio, E.T., Rosenfeld, L.K., Paduan, J.D., 1998. Observations of the internal tide in Monterey Canyon. Journal of Physical Oceanography 28, 1873-1903.

Pieper, R.E., Holliday, D.V., Kleppel, S., 1990. Quantitative zooplankton distributions form multifrequency acoustics. Journal of Plankton Research 12, 433-441.

Rees, J.-F., Wergifosse, B., Noiseti, O., Dubuissoni, M., Janssens, B., Thompson, E.M. 1998. The origins of marine bioluminescence: turning oxygen defence mechanisms into deep-sea communication tools. Journal of Experimental Biology 201, 1211-1221.

Schofield, O., Bergmann, T., Bissett, W.P., Moline, M.A., Orrico, C., 2004. Inverting inherent optical signatures in the nearshore coastal waters at the Long Term Ecosystem Observatory. Journal of Geophysical Research 109, C12S04.

Seliger, H.H., Fastie, W.G., McElroy, W.D., 1969. Towable photometer for rapid area mapping of concentrations of bioluminescent marine dinoflagellates. Limnology and Oceanography $14,806-813$.

Shulman, I., Haddock, S.H.D., McGillicuddy, D.J., Paduan, J.D., Bissett, W.P., 2003. Numerical modeling of bioluminescence distributions in the coastal ocean. Journal of Atmospheric and Oceanic Technology 20, 1060-1068.

Shulman, I., McGillicuddy Jr., D.J., Moline, M.A., Haddock, S.H.D., Kindle, J.C., Nechaev, D., Phelps, M.W., 2005. Bioluminescence intensity modeling and sampling strategy optimization. Journal of Atmospheric and Oceanic Technology $22,1267-1281$.

Soli, G., 1966. Bioluminescent cycle of photosynthetic dinoflagellates. Limnology and Oceanography 11, 355-363.

Swift, E., Sullivan, J.M., Batchelder, H.P., Van Keuren, J., Vaillancourt, R.D., Bidgare, R.R. 1995. Bioluminescent organisms and bioluminescence measurements in the North Atlantic Ocean near latitude $59.5 \mathrm{~N}$, longitude $21 \mathrm{~W}$. Journal of Geophysical Research 100, 6527-6547.

Thomas, C.R., 1997. Identifying marine Phytoplankton. Academic Press, San Diego, CA, p. 858

Widder, E.A., Case, J.F., 1981. Two flash forms in the bioluminescent dinoflagellate, Pyrocystis fusiformis. Journal of Comparative Physiology Acta 143, 43-52.

Widder, E.A., Case, J.F., Bernstein, S.A., MacIntyre, S., Lowenstine, M.R., Bowlby, M.R., Cook, D.P., 1993. A new large volume bioluminescence bathyphotometer with defined turbulence excitation. Deep-Sea Research 40, 607-627.

Widder, E.A., Johnsen, S., Bernstein, S.A., Case, J.F., Neilson, D.J., 1999. Thin layers of bioluminescent copepods found at density discontinuities in the water column. Marine Biology 134, 429-437.

Yentsch, C.S., Menzel, D.W., 1963. A method for the determination of phytoplankton chlorophyll and phaeophytin by fluorescence. Deep-Sea Research 10 221-231. 